\title{
Premature childbirth: pregnant women's characteristics of a population in the South area of São Paulo
}

\author{
Aline Zorzim Berger 1 \\ Vivian Inácio Zorzim 2 \\ Elias Ferreira Pôrto 3 \\ Fábio Marcon Alfieri 4 \\ 1-4 Centro Universitário Adventista de São Paulo.Estrada de Itapecerica, 5859. Jardim lae. São Paulo, SP, Brasil. CEP: $05.890-020$. \\ E-mail: fabioalfieri@usp.br
}

\begin{abstract}
Objectives: to identify the characteristics of pregnant women who had premature childbirth (PPT) in the South region of São Paulo city.

Methods: a cross-sectional observational study with a data collection of 122 medical files on pregnant women who had PPT in 2013. The collected data were analyzed by a statistical package, Graphpad Prism 6. As for the variables that were shown to be significant in the multivariate regression, an analysis was performed in a dichotomous form by odds ratio.

Results: the mean age of the pregnant women was 24.9 years old. Of the 122 pregnant women, $34.4 \%$ were included in the age group considered to be at risk by the Ministry of Health. The predominant race was mixed (46.2\%). $41.8 \%$ were high school graduates. Regarding to personal background, the history on urinary infection was mostly mentioned (37.5\%). In relation to family history regarding clinical conditions, $43 \%$ had diabetes history and $61 \%$ had hypertension. As for gynecological history, 37.5\% reported having dysmenorrhea during menstrual cycles. Multivariate analysis was performed and found that particularly hypertension and dysmenorrhea were the most significant.

Conclusions: Regarding to women's risk factors for premature childbirth, the most determining factor was dysmenorrhea, followed by hypertension.
\end{abstract}

Key words Premature labor, Women's health, Hypertension, Dysmenorrhea 


\section{Introduction}

Pregnancy and childbirth are unique events in the lives of women and their families. In Brazil, despite the efforts made during prenatal and childbirth, some problems remain by providing a current scenario of high rates of maternal and infant mortality and neonates morbidity, especially in preterm newborns. ${ }^{1-4}$

Premature childbirth (PPT) is the occurrence of birth before the term, in other words, less than 37 weeks of gestation, or between 140 and 257 days after the first day of the last menstrual period, regardless to birth weight, this may be classified as extreme prematurity when childbirth occurs before the $28^{\text {th }}$ week of gestation, premature birth occurs between the $28^{\text {th }}$ and 32 nd week of gestation and moderate prematurity is between the 32 nd and 37 th weeks. ${ }^{2}$

According to the related reasons, PPT can be classified as spontaneous when the consequence of spontaneous labor occurs as a result of itself or the rupture of the premature membranes, or induced, this occurs by medical indication due to maternal and/or fetal complications. 5

The most common maternal complications that stimulates PPT are severe preeclampsia, placenta previa, non-reassuring fetal state or premature placenta abruption. 6

According to Goldenberg et al.,3 most PPT occur spontaneously, however, the induced PPT rates have been increasing since 1990, currently corresponding to $20 \%$.

According to global action report elaborated by the World Health Organization (WHO) 15 million premature newborns are accounted for in the world every year, of which 1 million of them die. ${ }^{4}$

About $90 \%$ of these premature births are concentrated in developing countries, with 11 million cases in Africa and Asia and the rest of the Latin America and the Caribbean. ${ }^{7}$

In Brazil, a tendency of prematurity increase has been observed. The percentage ranged from $5 \%$ in $1994,6.6 \%$ in 2005 . Currently is $10.5 \%$. 2,8

In São Paulo city, $12.3 \%$ of the births which occurred in 2012 were premature infants, demostrating one of the main health problems. More precisely in the South region - Technical Health Supervision of Campo Limpo (STSCL) - this is where the study was conducted and the rate was $12.9 \% .^{9}$

There is difficulty in preventing PPT due to the multiplicity of causes and precipitating factors and of the complex pathophysiology. The main factors on maternal risk related to spontaneous PPT are: personal history of PPT, multiple pregnancy, low socioeconomic status, Afro-American descendent, extreme weight: low weight or obesity, extreme age: $<16$ or $>35$ years, smoking, stress, genital tract infection, premature rupture of the membranes, antepartum hemorrhage, cervical insufficiency, congenital uterine anomalies, fragility on prenatal care. 10,11

It is known that spontaneous or induced, PPT represents a great challenge for the public health services around the world, because it is the main cause of neonatal death, besides being responsible for the greater part of morbidities, including cerebral palsy, cognitive impairment, blindness, deafness and respiratory diseases. Together, the morbidities contribute to the loss of more than 100 million years of adjusted life for incapacity.4,12 And without taking into account the increase of the economic cost in health. 13

The recognition and the reduction of maternal and fetal risk factors, as well as the monitoring of perinatal morbimortality are essential to improve the quality of the health services and the possibility to decrease maternal-fetal complications in relation to PPT.5

Branches and Cuman 14 affirm that the knowledge on the characteristics of a populational group contributes to the indice reduction of health indicators, especially the coefficient infant mortality rate. Therefore, a continuous evaluation of these health indicators by the public administration will provide strategies for integral care to children and instruments to reduce the incidence of infant morbimortality.

As the arising causes of PPT are still diverse and this event has been increasing in countries like Brazil, especially in the South region of São Paulo city, it is necessary to know the characteristics of the pregnant women who had PPT. The search of these information becomes a starting point for future actions in regards to promoting health at this stage of the woman's life and the future newborn. Therefore, the objective of this study was to identify the characteristics of pregnant women who had premature childbirth in the South region of São Paulo city.

\section{Methods}

This is a cross-sectional observational study on the characteristics of pregnant women and prenatal care of those who had premature childbirth in the South region (Capão Redondo) in São Paulo city in 2013. 
This study was approved by the Research Ethics Committee in the Secretaria Municipal da Saúde de São Paulo, document number: 805.666.

This study was carried out at 12 Basic Health Units (UBSs) inserted in the district of Capão Redondo, which meets the National Program (PN) through the Family Health Program (PSF). The population of this study was consisted by pregnant women enrolled at the respective UBSs, included in the PN, who had a childbirth delivery with the gestational age between 20 to 36 weeks and six days in the year of 2013 .

In 2013, 249 pregnant women who had PPT, had been enrolled in the PN at the studied UBSs. Of these pregnant women, 122 agreed to be part of the research by data collecting their respective patient files, 118 had moved away, 5 did not accept to be part of the research and 4 did not have their medical files found.

A selection of pregnant women who had PPT in 2013 was performed by the Integrated Care Management System (SIGA). While performing the selection, the patient's files were identified and constituted by data sources.

For the data collection, a developed instrument was used based on the Medical Files to Accompany the Pregnancy of Mothers in São Paulo Program (Prontuário de Acompanhamento da Gestação do Programa Mãe Paulistana).

The pregnant woman's medical files was composed by the registration of SISPRENATAL, by the prenatal file and by the evolution sheet used at the UBSs which constitutes data sources.

The developed instrument for this study, included the number of SISPRENATAL, number of the medical files, the name of the UBS, sociodemographic data, family history, personal history, gynecological history, neonatal history, data of consultations, vaccination, supplementation, exams, complications and childbirth data.

The collected data were analyzed by a statistical package, Graphpad Prism 6.0, used for Windows program where the anthropometric and clinical characteristics evaluated on patients were described with the use of absolute and relative frequencies (mean, standard deviation and 95\% confidence interval).

For the variables that were shown to be significant within the multivariate regression were analyzed in a dichotomous form by odds ratio (OR). In all the analyzes, a significance level of $5 \%$ $(p<0.05)$ was adopted.

\section{Results}

The mean age of the pregnant women surveyed was $24.9 \pm 6.9$ years old, observing that the youngest was 14 and the oldest was 31 years old. Table 1 shows that of the 122 pregnant women, in other words, 42 (34.4\%) pregnant women were included in the age range considered to be at risk by the Ministry of Health (MS), $73.8 \%$ were less than 20 years of age and $26.1 \%$ were older than 35 .

The predominant race was mixed with $46.2 \%$, $41.8 \%$ graduated from high school, $32.5 \%$ lived with relatives without a partner, very close to $31.6 \%$ lived with a partner and children and as for martial status, $43.6 \%$ reported to be single.

Most of the pregnant women $(59.2 \%)$ were unemployed. In relation to family income, $50 \%$ of the pregnant women had a family income of 1 to 2 minimum wage. The other half of the pregnant women surveyed were divided in $20.3 \%$ with less than 1 minimum wage, $20.3 \%$ with 2 to 3 minimum wages, $7.4 \%$ with 3 to 4 minimum wages and $1.85 \%$ with 6 to 7 minimum wages.

In regards to family history relating to clinical conditions, $43 \%$ had diabetes history and $61 \%$ had hypertension.

In relation to personal history, what highlighted the most was urinary infection $(37.5 \%)$ as shown in Table 2.

Of the 122 women, $14.7 \%$ smoked, $5.7 \%$ consumed alcohol and $4.13 \%$ used illicit drugs.

As for the gynecological history, the mean age of the menarche was $13 \pm 3.94$ years old. The mean of the menstrual duration was 5.1 days with an interval of 29.1 days between one cycle and another. $64.8 \%$ reported having a regular menstrual cycle and $37.5 \%$ reported having dysmenorrhoea during menstrual cycles.

In relation to sexual activity, the mean age for the onset of sexual life was 16.1 years old. $83.1 \%$ referred having only one partner in the past year.

A little more than half (52.7\%) of the women had already used contraceptive methods, oral contraceptive was the most mentioned method.

In relation to the women's obstetric history, these women had an average of $2.26 \pm 1.65$ pregnancies. And of these childbirths, $74.7 \%$ were vaginal delivery.

In relation to the main complaints of pregnant women in the beginning of the pregnancy were, hyperemesis $(41.6 \%)$, lower abdominal pain $(36.4 \%)$, urinary alterations $(9.3 \%)$, bleeding $(10.3 \%)$, leukorrhea $(18.3 \%)$, and among other less frequent. 
Table 1

Distribution of pregnant women, according to sociodemographic variables. São Paulo, 2013.

\begin{tabular}{|c|c|c|}
\hline Variables & $N=122$ & $\%$ \\
\hline \multicolumn{3}{|l|}{ Age range of risk $(n=42 ; 34.4 \%)$} \\
\hline$<20$ years old & 31 & 73.8 \\
\hline$>35$ years old & 11 & 26.1 \\
\hline \multicolumn{3}{|l|}{ Race/Color informed $(n=119 ; 97.5 \%)$ * } \\
\hline White & 42 & 35.2 \\
\hline Black & 18 & 15.1 \\
\hline Mixed & 55 & 46.2 \\
\hline Yellow & 4 & 3.3 \\
\hline Indian & 0 & - \\
\hline \multicolumn{3}{|l|}{ Schooling $(n=117 ; 95.9 \%)^{*}$} \\
\hline Does not know how to read/write & 0 & - \\
\hline Incomplete elementary schooling & 21 & 17.9 \\
\hline Complete elementary schooling & 18 & 15.3 \\
\hline Incomplete High School Graduate & 25 & 21.3 \\
\hline Complete High School Graduate & 49 & 41.8 \\
\hline Incomplete Undergraduate & 1 & 0.8 \\
\hline Complete Undergraduate & 3 & 2.5 \\
\hline Post Graduation & 0 & - \\
\hline \multicolumn{3}{|c|}{ Family situation/Living with $(n=120 ; 98.3 \%)$ * } \\
\hline Partner and children & 38 & 31.6 \\
\hline Partner and without children & 31 & 25.8 \\
\hline Partner, children and relatives & 8 & 6.6 \\
\hline Relatives and without a partner & 39 & 32.5 \\
\hline Other people & 1 & 0.8 \\
\hline Living alone & 3 & 2.5 \\
\hline \multicolumn{3}{|l|}{ Marital Status/ Union $(n=119 ; 97.5 \%)^{*}$} \\
\hline Married & 32 & 26.8 \\
\hline Single & 52 & 43.6 \\
\hline A stable union & 34 & 28.5 \\
\hline Separated/divorced & 1 & 0.8 \\
\hline Widow & 0 & - \\
\hline
\end{tabular}

*Justifies the alteration in $\mathrm{N}$ different from 122 in the variables due to the lack of information from the data sources. 
Table 2

Distribution of pregnant women, according to personal history. São Paulo, 2013.

\begin{tabular}{|c|c|c|}
\hline Variables & $\mathrm{N}=120 *$ & $\%$ \\
\hline \multicolumn{3}{|l|}{ Urinary infection } \\
\hline Yes & 45 & 37.5 \\
\hline No & 75 & 62.5 \\
\hline \multicolumn{3}{|l|}{ Infertility } \\
\hline Yes & 0 & - \\
\hline No & 120 & 100.0 \\
\hline \multicolumn{3}{|l|}{ Heart disease } \\
\hline Yes & 6 & 5.0 \\
\hline No & 114 & 95.0 \\
\hline \multicolumn{3}{|l|}{ Diabetes } \\
\hline Yes & 3 & 2.5 \\
\hline No & 117 & 97.5 \\
\hline \multicolumn{3}{|l|}{ Hypertension } \\
\hline Yes & 11 & 9.1 \\
\hline No & 109 & 90.8 \\
\hline \multicolumn{3}{|l|}{ Pelvic /Uterine Surgery } \\
\hline Yes & 15 & 12.5 \\
\hline No & 105 & 87.5 \\
\hline \multicolumn{3}{|l|}{ Malformation } \\
\hline Yes & 0 & - \\
\hline No & 120 & 100.0 \\
\hline \multicolumn{3}{|l|}{ Sexually transmitted disease } \\
\hline Yes & 2 & 1.6 \\
\hline No & 118 & 98.3 \\
\hline \multicolumn{3}{|c|}{ Other pathological conditions $(n=119)$} \\
\hline Yes & 9 & 7.6 \\
\hline Cerebrovascular Accident & 1 & 0.8 \\
\hline Anemia & 1 & 0.8 \\
\hline Bronchitis & 1 & 0.8 \\
\hline Renal Calculus & 1 & 0.8 \\
\hline Thyroid Cancer & 1 & 0.8 \\
\hline Behcet's disease & 1 & 0.8 \\
\hline Mental Illness & 1 & 0.8 \\
\hline Inguinal Hernia & 1 & 0.8 \\
\hline Hypothyroidism & 1 & 0.8 \\
\hline No & 110 & 92.4 \\
\hline
\end{tabular}

*Justifies the alterations in $\mathrm{N}$ different from 122 in the variables due to the lack of information in the data sources. 
Table 3

Distribution of pregnant women according to the risk analysis for premature childbirth in hypertensive pregnant women. São Paulo, 2013.

\begin{tabular}{lcc}
\hline \multicolumn{1}{c}{ Variables } & OR & Cl95\% \\
\hline Hypertension vs. Anemia & 15.7 & $2.0-121$ \\
Hypertension vs. Diabetes & 3.9 & $1.06-14.4$ \\
Hypertension vs. Illicit Drugs & 3.3 & $1.6-9.4$ \\
Hypertension vs. STDs & 5.9 & $1.2-27.4$ \\
Hypertension vs. Bleeding & 1.2 & $0.5-2.8$ \\
Hypertension vs. Smoking & 1.2 & 0.01 \\
& & 0.01 \\
\hline
\end{tabular}

STDs = sexually transmitted diseases; OR= odds ratio; $\mathrm{ns}=$ not significant.

Table 4

Distribution of pregnant women according to the risk analysis for premature childbirth in pregnant women with dysmenorrhea. São Paulo, 2013.

\begin{tabular}{lcc}
\hline \multicolumn{1}{c}{ Variables } & OR & CI95\% \\
\hline Dysmenorrhea vs. Diabetes & 3.8 & $1.8-5.6$ \\
Dysmenorrhea vs. Hypertension & 4.2 & $2.0-8.6$ \\
Dysmenorrhea vs. Urinary infection & 2.7 & $1.5-5.0$ \\
Dysmenorrhea vs. Regular Menstruation & 3 & $1.6-5.7$ \\
Dysmenorrhea vs. Smoking & 1.8 & 0.01 \\
\hline
\end{tabular}

OR= odds ratio; ns = not significant.

With the objective of verifying the factors that could interfere so that the pregnant women would have PPT, a multivariate analysis was performed as a variable outcome of PPT. It was verified that hypertension and dysmenorrhoea were the variables that showed significant differences. Afterwards, a risk analysis of these variables against the others that were not significant in multivariate analysis was performed. Data in Tables 3 and 4 show the results of the risk analysis of these two variables comparing with the others. It was found that the risk of PPT in hypertensive patients was greater than the risk in women with diabetes, sexually transmitted diseases, anemia and those who took illicit drugs. It was also verified that the risk was increasing in women with dysmenorrhoea in relation to women with hypertension, regular menstruation and diabetic.

\section{Discussion}

The objective of this study was to outline some aspects of the women's profile of those that had premature childbirth in the South region of São
Paulo city. In relation to sociodemographic characteristics, the mean age of the studied women was 24.9 years old, the similar age found in another study by Guimarães and Melo15 that the mean was 25.8 years old in women who had premature childbirths in a public hospital in the city of Rio de Janeiro.

It is noteworthy that more than one third of the pregnant women were in the risk age group, in other words, less than 20 years old and more than 35 . A case control research on risk factors for premature childbirth in Bangkok affirms that women younger than 20 years old compared to women between 25 and 29, have 1.69 more chances of having PPT and those who are more than 35 years old present a higher risk of 1.75 times more. 16

The predominant race was mixed with $46.2 \%$, similar to Almeida et al. ${ }^{17}$ study claiming that the predominant race of women who had PPT in a public maternity hospital in the city of Imperatriz, MA, were also mixed. The results of these studies are similar, possibly due to the fact that the vast majority of the women who were attended at a public health service to be in the $\mathrm{PN}$, belonged to the same race. 
According to Lansky et al. 18 research, $54.65 \%$ of the women who had their children between February 2011 and October 2012 in Brazil were also mixed race.

In relation to schooling, more than $40 \%$ of the pregnant women were high school graduates, a lower number when compared to Guimarães and Melo ${ }^{15}$ research which claim that more than half of the women surveyed who had PPT were high school graduates. Probably this level of schooling reflect on the lack of conditions to have access to superior levels of schooling, as well as the low socioeconomic situation of this population is also found in other studies. ${ }^{5,15,19,20}$ It is believed that having less financial conditions, may bring a higher risk of premature childbirth due to the lack of access of information and personal care such as hygiene and food. Another fact was found that almost one third of the pregnant women lived with relatives and without a partner, being single was the predominated marital status with $43.6 \%$. These data corroborate with other researches. 5,21

In relation to the use of licit and illicit drugs, $14.7 \%$ of the pregnant women smoked, $5.7 \%$ consumed alcohol and $4.13 \%$ used illicit drugs, among them, crack and cocaine were used. According to Barbosa et al.22 the consumption of alcohol during pregnancy can cause Fetal Alcohol Syndrome that is characterized by craniofacial alterations, growth and development disorder and dysfunction in the central nervous system. All alcoholic beverages consumed by pregnant woman passes through the placental barrier, where the fetal exposure is greater because the metabolism and the elimination are slower, causing the amniotic liquid to remain impregnated with alcohol. Miyake et al. ${ }^{23}$ informed that according to a survey conducted in Okinawa, Japan, the consumption of $1.0 \mathrm{~g}$ or more of alcohol per day during the pregnancy is significantly associated to PPT. As for smoking, Moutinho and Alexandra 24 claim that through the results of their research, smoking represents a significant risk factor for prematurity, compared to pregnant women who were nonsmokers. 22

In relation to the mentioned diseases, hypertension was the predominant disease, existing in more than half of the family history. Hypertension is known to complicate approximately 7 to $10 \%$ of all the pregnancies, incidence which may vary with the population studied and the criteria used for the diagnosis. It is the most common complication in pregnancy and the main cause of maternal and perinatal morbimortality, therefore, any possibility of developing hypertension during pregnancy should be monitored. 1,3,8

It is important to emphasize that although more than half of the pregnant women had referred hypertension in their family history, a small number was verified, $9.1 \%$ reported having hypertension before becoming pregnant. This data is similar to the survey carried out by Assunção et al. 19 claming that $8.8 \%$ of the studied pregnant women reported prior hypertension. High levels of maternal blood pressure are associated with the impairment of the fetal growth during the third trimester of pregnancy, and increases the risks of adverse outcomes such as preterm birth and perinatal death. There are reports that $11 \%$ of childbirths between $34^{\text {th }}$ to $37^{\text {th }}$ week of gestation are women who developed preeclampsia and in case of recurrence, this doubles to $22 \%$. Also, in this study, we pointed out that $33 \%$ of premature infants from pregnancy with preeclampsia need intensive care. This becomes clear that Hypertension Syndrome in Pregnancy (SHGs) favors premature childbirth and a consequent hospitalization in the Neonatal ICU, are however, considered as high risk pregnancy and perinatal. 1

Some authors have also concluded that the presence of hypertensive syndromes in pregnancy is associated to PPT. 19,20,25

Another factor related to the disease, but in relation to the previous diseases among the pregnant women studied, there was the existence of urinary tract infection history presented about $37.5 \%$, in other words, more than a third of the pregnant women.

The urinary tract infections (ITUs) are considered the second type of infection detected and can be treated, falling behind only to respiratory infections, representing a common problem in primary care because it is mainly caused by the lack of hygiene and low water intake. It estimates that a woman has greater susceptilibilidade to have ITU because the urethra is shorter and the greater proximity between the vestibule and the anus, therefore, hygiene factor is the utmost importance in preventing ITUs. During the pregnancy, the presence of ITU is more common due to the physiopathological changes (mechanical and hormonal) that occur during this phase. The smooth muscle of the bladder has its power to decrease contraction, allowing the accumulation of microorganisms in its interior due to the not total removal of the urine at the moment. Therefore, it is necessary to increase the water intake so that the microorganisms do not accommodate too long in the bladder and the urethral canal. ${ }^{26}$

In addition to the presence of hypertension, the presence of dysmenorrhea history also has emerged 
as a significant factor for the occurrence of PPT. Dysmenorrhea is a gynecological disorder characterized by pain in the lower abdomen that may radiate to the thighs and the top and the bottom of the vertebral column, commonly associated to nausea, headache, fatigue and diarrhea, symptoms which appear commonly on the day before or on the first day of the menstrual flow, disappearing at the end of the menstruation period. 27

Few reports exist regarding the presence of dysmenorrhea as a risk factor for PPT. Bayram et al. 28 conducted a test to evaluate previous pelvic pain in 57 pregnant women and found that those who had pain related to dysmenorrhea, had PPT. Juang et al. 29 conducted a research with 329 single pregnant women, concluding that those who presented a history of dysmenorrhea had a higher risk for the occurrence of spontaneous PPT and premature rupture of membranes. But in a study conducted by Tayebeh et al. 30 in Iran, concluded that there is no relation between dysmenorrhea and PPT.

Therefore, it is necessary to intensify the work in previous identification of risk factors and health promotion during PN by a multidisciplinary team that comes in contact with these women. As the community agent who knows your home and your life habits, even the physician who prescribes the medication to control the blood pressure levels as well as guides and requires you to practice physical exercise, in order to decrease dydmenorrhea. In addition to the medication, the whole team should encourage a healthy lifestyle, prioritizing the consumption of natural foods without preservatives and the achievement of physical exercises suitable for the gestation.

There have been no reports that describe the possible biological reasons that may relate dysmenorrhea to PPT. We may raise some hypothesis as the constant uterine contraction during a woman's life. Therefore, upon these considerations, through the data of this study, there is a need for further research to investigate the relation between dysmenorrhea and prematurity, for which, preventive measurements should be taken. However, issues such as hypertension and dysmenorrhea should already be previously observed in women who intend to be mothers so that there is a decrease in the probability of having premature childbirths. It is believed that general interventions such as a regular physical activity, proper medication and among others may have effect on these important clinical conditions as seen in this study, which may affect these pregnant women's childbirth.

Some of the main characteristics of women who had premature childbirth were: the mean age was 25 years old, mixed race, high school graduates, single, surviving on less than one or even two minimum wages.

In relation to risk factors of women's premature childbirth, dysmenorrhea was the most important factor, followed by hypertension.

\section{References}

1. Souza LF, Botelho NM. Fatores de risco para o parto prematuro em puérperas que tiveram parto pretermo. Rev Para Med. 2011;25(4).

2. Organização Mundial da Saúde. Parto Prematuro. 2013. [acesso em 24 jun 2013]. Disponível em: http://who.int/mediacentre/factsheets/fs363.

3. Goldenberg RL, Culbane JF, Iams JD, Romero R. Epidemiology and causes of preterm birth. Lancet. 2008; 371: 75-84.

4. Howson CP, Kinney MV, McDougall L, Lawn JE. Born too soon: The global action report on preterm birth. Geneva: World Health Organization; 2012. Disponível em: http://www.who.int/pmnch/media/news/2012/201204_born toosoon-report.pdf

5. Silva LAS, Rojas PFB, Laus FFL, Sakae TM. Fatores de risco associados ao parto pré-termo em hospital de referência de Santa Catarina. Rev da AMRIGS. 2009; 53: 35460 .

6. Júnior MDC, Fonseca ESVB, Calisto AC, Evangelista
AA.Predição e prevenção do parto pré-termo espontâneo. Rev Med. 2013; 23: 330-5.

7. Morisaki N, Togoobaatar G, Vogel JP, Souza JP, Hogue CJR, Jayaratne K, Ota E, Mori R. Risk factors for spontaneous and provider - initiated preterm delivery in high and low human development index countries: a secondary analysis of the world health organization multicountry survey on maternal and newborn health. BJOG. 2014; 121 : 101-9.

8. Nascer do Brasil. Inquérito nacional sobre parto e nascimento. 2013. [acesso em 07 nov 2013]. Disponível em: http://www.ensp.fiocruz.br/nascerbrasil/.

9. SINASC. Dados e Indicadores para a Saúde. 2013. [acesso em 6 nov 2013].Disponível em: http://www.prefeitura. sp.gov.br

10. Beck S, Wojdyla D, Say L, Betran AP, Merialdi M, Requejo JH, Rubens C, Menon R, Look PFAV, The worldwide incidence of preterm birth: a systematic review of maternal mortality and morbidity. Bull World Organ. 2010; 88: 31-8. 
11. Hass DM. Preterm Birth. Clin Evid. 2006; 15: 1966-85.

12. Lawn JE, Cousens S, Zupan J. 4 million neonatal deaths: When? Where? Why? Lancet. 2005; 365: 891-900.

13. Russel RB, Green NS, Steiner CA, Meikle S, Howse JL, Poschman K, Dias T, Potetz L, Davidoff MJ, Damus K, Petrini JR. Cost of hospitalizations for preterm and low birth weight infants in the United States. Pediatrics. 2007; 120: $1-9$.

14. Ramos HAC, Cuman RKN. Fatores de Risco para Prematuridade: Pesquisa Documental. Esc Anna Nery Rev Enferm. 2009; 13: 297-304.

15. Guimarães EC, Melo ECP. Características do apoio social associado à prematuridade em uma população de puérperas de baixa renda. Esc Anna Nery. 2011; 51-61.

16. Ip M, Peyman E, Lohsoonthorn V, Williams MA. A case control study of preterm delivery risk factors. J Obstet Gynaecol Res. 2010; 36: 34-44.

17. Almeida AC, Jesus ACP, Lima PFT, Araújo MFM, Araújo TM. Fatores de risco maternos para prematuridade em uma maternidade pública de Imperatriz - MA. Rev Gaúcha Enferm. 2012; 33: 86-94.

18. Lansky S, Friche AAL, Silva AAM, Campos D, Bittencourt SDA, Carvalho ML, Frias PG, Cavalcante RS, Cunha AJLA. Pesquisa Nascer no Brasil: perfil da mortalidade neonatal e avaliação da assistência à gestante e ao recémnascido. Cad Saúde Pública. 2014; 30: 192-207.

19. Assunção PL, Novaes HMD, Alencar GP, Melo ASO, Almeida MF. Fatores associados ao nascimento pré-termo em Campina Grande, Paraíba, Brasil: um estudo caso-controle. Cad Saúde Pública. 2012; 28: 1078-90.

20. Silva AM, Almeida MF, Matsuo T, Soares DA. Fatores de risco para nascimentos pré-termo em Londrina, Paraná, Brasil. Cad Saúde Pública. 2009; 25: 2125-38.

21. Aragão VMF, Silva AAMS, Aragão LF, Barbieri MA Bettiol H, Coimbra LC, Ribeiro VS. Fatores de risco para prematuridade em São Luis, Maranhão, Brasil. Cad Saúde Pública. 2004; 20: 57-63.

Received on June 30, 2016

Final version presented on October 6, 2016

Approved on November 29, 2016
22. Barbosa CS, Libório AGS, Flores DM, Mendes RCD, Schmitz WO. Rastreamento do uso de álcool e Tabaco por gestantes atendidas no serviço público de saúde de um município do Mato Grosso do Sul. Nutrire. 2013; 38: 115.

23. Miyake Y, Tanaka K, Okubo H, Sasaki S, Arakawa M. Alcohol consumption during pregnancy and birth outcomes: the Kyushu Okinawa Maternal and Child Health Study. BMC Pregnancy Childbirth. 2014; 14: 79.

24. Moutinho A, Alexandra D. Parto pré-termo, tabagismo e outros fatores de risco - um estudo caso controle. Rev Port Med Geral Fam. 2013; 29: 107-112.

25. Souza NL, Araújo ACPF, Costa ICC. Representações sociais de puérperas sobre as síndromes hipertensivas da gravidez e nascimento prematuro. Rev Latino Am. Enfermagem. 2013; 21(3)

26. Baumgarten MCS, Silva VG, Mastalir FP, Klaus F, D'azevedo PA. Infecção urinária na gestação: uma revisão da literatura. Unopar Científica. 2011; 13.

27. Araújo LM, Silva JMN, Bastos WT, Ventura PL. Diminuição da dor em mulheres com dismenorréia primária, tratadas pelo método Pilates. Rev Dor. 2012; 13 : 119-23.

28. Bayram C, Osmanagaoglu MA, Aran T, Guven S, Bozkaya $\mathrm{H}$. The effect of chronic pelvic pain scoring on pre-term delivery rate. J Obstet Gynaecol. 2013; 33: 32-7.

29. Juang CM, Yen MS, Twu NF, Horng HC, Yu HC, Chen CY. Impacto of pregnancy on primary dysmenorrhea. Int $\mathrm{J}$ Gynaecol Obstet. 2006; 92: 221-7.

30. Tayebeh NB, Mohsen R, Mozhgan J, Ali AJ. The relation between primary dysmenorrhea and spontaneous preterm labor in primiparous womens in Rafsanjan. Iranian J Obst Gyneocol Fertility. 2012; 14: 37-43. 